\title{
Personalized Paths for Physical Activity: Developing a Person-Centered Quantitative Function to Determine a Customized Amount of Exercise and Enhancing Individual Commitment
}

\section{Giovanni lolascon}

University of Campania "Luigi Vanvitelli"

Francesca Gimigliano

University of Campania "Luigi Vanvitelli"

Gioconda Di Pietro

University of Campania "Luigi Vanvitelli"

Antimo Moretti ( $\sim$ antimo.moretti@unicampania.it )

Università degli Studi della Campania Luigi Vanvitelli Dipartimento Multidisciplinare di Specialita Medico-Chirurgiche e Odontoiatriche https://orcid.org/0000-0002-4598-2891

\section{Marco Paoletta}

University of Campania "Luigi Vanvitelli"

Matteo Rivezzi

University of Foggia

Alessandro Distante

Euro Mediterranean Scientific Biomedical Institute

Prisco Piscitelli

Federico II University

Research article

Keywords: Physical activity, Exercise, Personalized approach, Healthy lifestyle, Metabolic Equivalents

Posted Date: December 30th, 2020

DOl: https://doi.org/10.21203/rs.3.rs-134870/v1

License: (9) (1) This work is licensed under a Creative Commons Attribution 4.0 International License.

Read Full License 
2 Personalized Paths for Physical activity: Developing

\title{
a Person-centered Quantitative Function to
} Determine a Customized Amount of Exercise and enhancing Individual Commitment

\author{
Giovanni Iolascon 1, Francesca Gimigliano ${ }^{2}$, Gioconda Di Pietro ${ }^{1}$, Antimo Moretti 1, Marco \\ Paoletta $^{1}$, Matteo Rivezzi ${ }^{3}$, Alessandro Distante ${ }^{4}$ and Prisco Piscitelli 4,5 \\ 1 Department of Medical and Surgical Specialties and Dentistry, University of Campania "Luigi Vanvitelli", \\ Naples, Italy \\ 2 Department of Mental and Physical Health and Preventive Medicine, University of Campania “Luigi \\ Vanvitelli", Naples, Italy \\ 3 Doctorate in Translational Medicine, University of Foggia, Foggia, Italy \\ 4 Euro Mediterranean Scientific Biomedical Institute, ISBEM, Bruxelles, Belgium \\ 5 Staff UNESCO Chair on Health Education and Sustainable Development, Federico II University of Naples, \\ Naples, Italy \\ * Correspondence: Correspondence: antimo.moretti@unicampania.it; Tel.: +390815665537
}

Received: date; Accepted: date; Published: date

\begin{abstract}
:
Background: Non-Communicable Diseases (NCDs) are leading causes of mortality. These conditions are also known as chronic diseases of long duration and generally slow progression. Physical activity is a main factor to delay symptoms and consequences of NCDs. In last decades, reduced physical exercise has been observed across all ages. Despite educational campaigns aimed at modifying unhealthy habits, it is difficult to promote healthy lifestyles in general population. Poor interest, lack of motivation, as well as career and family commitments hinder people's participation in regular physical activity programs. In this study we propose a theoretical person-centred approach to actively involve general population in enhancing their opportunity to perform physical activity on the basis of personalized needs and targets.
\end{abstract}

Methods: We defined four profiles of baseline physical activity levels (inactive, moderately inactive, moderately active, and active people) by referring to Metabolic equivalents (METs) on the basis of individual answers to General Practice Physical Activity Questionnaire (GPPAQ). Based on the answers to the GPPAQ and by computing the related METs for each profile of baseline exercise levels, we developed an innovative person-centered web-based algorithm/function for enhancing and measuring physical activity participation in community settings. This function is able to compute evidence-based standardized profiles of participants, personalized goals of physical activity being functional to the purpose of maintaining or gaining health benefits, as well as the type and duration of physical activity needed to reach these goals.

Conclusion: It might be speculated that this approach would be a reliable method for increasing people's self-efficacy and population adherence to recommended levels of physical activity. However, this theoretical proposal requires to be implemented in further research.

Keywords: Physical activity; Exercise; Personalized approach; Healthy lifestyle; Metabolic Equivalents 
The epidemiological explosion of Non-Communicable Diseases (NCDs) is one of the main concerns of the health systems representing the leading causes of annual deaths worldwide [1].

Non-Communicable Diseases, also known as chronic diseases, affect many adults and are characterized by slow and age-associated progression. Despite a higher prevalence of these conditions in older populations, surprisingly over 9 million deaths attributable to NCDs, such as cardiovascular and respiratory diseases, type 2 diabetes, and cancers, occur in younger people, without significant difference between men and women [2]. Most risk factors for NCDs could be modified through effective interventions, particularly addressing tobacco use, unhealthy diet, and physical inactivity [3]. Educational campaigns of both governments and non-governmental organisations aiming to modify unhealthy habits in general population have a limited impact on entrenched habits [4]. Indeed, it is historically known that people have serious difficulties in defining, understanding and adopting healthy lifestyles, even in those cases in which they are aware of the detrimental consequences deriving from the non-observance of such behaviours [5].

In this context, WHO supports a new concept based on people empowerment, shifting from a delivered healthcare model to a person-centred approach where the stakeholder is actively involved in maintenance or improvement of their health status, such as increasing levels of physical activity (PA) [6]. Even if beneficial effects of exercise have been widely documented, in the last decade a worrying decline in PA practice has been observed across all ages, including even children and adolescents. For example, it has been estimated that on a typical week, $40 \%$ of adults in Europe engaged in no exercise or sports [7]. Among the main reasons behind these data is that around $0 \%$ of Europeans report that they have not enough time to be engaged in exercise and $20 \%$ of them report that they are not interested in exercise at all and that they prefer to spend their time to do other activities [7]. Physical activity is not a priority due to social, cultural and economic reason: physical activity costs money, the rewards are often unclear to the public. There is no strong advice from the health system and policy makers. For example, if physical activity will be covered by health insurance, it is likely that many more people will participate in such activities. If physicians will advise physical activities to NCDs patients, and a progress will be monitored it is expected that those patients will follow these recommendations.

In order to enhance people insights about effectively promotion of a healthy lifestyle, is mandatory to define different types of PA [8]. This is defined as any movement of the body resulting from the contraction of skeletal muscles that increases energy expenditure above a basal level. Physical activity can be divided in unstructured (PA incorporated in daily life) or structured, defined as exercise that is a PA planned and repetitive. Therefore, PA includes also occupational, household as well as leisure-time activities [9]. Other environmental prevention strategies that may enhance participation in regular PA is to plan and conduct successful communication campaigns as well as to increase the opportunity to be involved in this activity [1]. This study was aimed at defining standardised profiles of recommended PA and to develop both personalized goals for general population, considering the needs of each category of people for increasing or maintaining the level PA, as well as the algorithms (type and duration of exercise) needed to reach these goals.

\section{Methods}

\section{Definition of standardized profiles of recommended physical activity level}

We have defined the following standard of PA, namely the volume of PA, expressed in Metabolic equivalents (METs), being functional to the purpose of gaining health benefits: an overall volume of weekly PA (3-5 times/week) to meet a minimum of 150 minutes of moderate-intensity activities or 75 minutes of vigorous-intensity activities $\left(150 * 3.0-5.9 \mathrm{MET}=450-885\right.$ METs or $75^{*} 6$ or more $=450$ or more METs) up to 300 minutes of moderate-intensity activities or 150 minutes of vigorous-intensity activities (300*3.0-5.9 MET $=900-1770$ METs or $150 * 6$ or more $=900$ or more METs), regardless of gender and age. However, the proposed model is designed to run through software that 
preliminarily takes into account age, gender and any disease of users that may limit the practice of

95 PA before accessing the algorithm.

\section{Definition of different individual goals of physical activity}

The proposal of a goal of PA to the user will make based on the following tenets.

1) The user will be classified in accordance to the level of current PA. The user will be advised to adopt the defined goal according to the type of person the user has been classified (i.e. people having the same level of activity take advantage by assuming " $X$ " as level of PA).

2) The standard will be hierarchically differentiated - namely a distinction between basic and advanced standard will be put. Basic goal is the amount of PA (900 METs) associated with substantial health benefits. Advanced goal is the amount of PA (1800 METs) associated with additional health benefits. Each user will be asked to choose the level of goal to be assumed as own purpose (needless to say, s/he will have the chance to update it over the time).

3) A dynamic architecture of goals has been designed, namely an architecture that considers the reaching of a certain goal for the adoption of a further, more advanced goal. Thanks to such a dynamic architecture, it will be possible to define incremental path enabling user to adopt intermediate goals being more consistent with their condition and to take advantage from the motivating effect of the experience of reaching and keeping what they define as goal. It is worth highlighting the conceptual difference with the distinction proposed in the previous point. In this case the different amount of PA is put at the service of the design of an incremental plan of activity; instead, the distinction considered in the previous point concerns the absolute level of PA (and therefore of health advantage) the user chose as own standard.

\section{Segmentation of users and identification of prototypical models of activity}

Users will be segmented in accordance to their current volume of PA, esteemed by means of the self-report General Practice Physical Activity Questionnaire (GPPAQ) [10]. ${ }^{1}$ To this end will be adopted the following 4 profiles of current activity, based on the GPPAQ:

$$
\text { - Inactive people }
$$

${ }^{1}$ Physical activity has been defined by WHO as "any bodily movement produced by skeletal muscles that requires energy expenditure". It is important to take in mind this definition when discussing on how to define its assessment. There are many available subjective (self-report questionnaires) and objective (indirect calorimetry, direct observation, heart rate telemetry, and movement sensors) methods to assess PA. All of them have well-known limitations. Movement sensors such as accelerometers are quite popular being able to give an objective measure of PA and being of relatively small size, however, due to their high costs, they are not usually practical in large-scale cohort studies where questionnaires are preferred. Recent reviews have documented up to 85 self-administered PA questionnaires for adults. The most important features of a selfadministered questionnaire are simplicity, cultural equivalency (translatability and international comparability), repeatability, construct validity, sensitivity and specificity, reliability, economy. Considering all these characteristics, the most suitable PA questionnaire, for the purpose of our project, is the General Practice Physical Activity (GPPAQ). This is a reliable and validated tool to assess adult level of physical activity via seven questions for use within primary care and its use is supported by the National Institute for Health and Care Excellence (NICE). To complete the GPPAQ only 60 seconds are necessary. It generates a simple, 4level PA index, categorizing patients as: active, moderately active, moderately inactive or inactive. In response to NICE public health guidance 2 (2006), which endorsed brief interventions in primary care to increase PA, the GPPAQ has been used in a UK public health initiative, the 'Let's Get Moving' campaign to identify inactive patients in primary care. The Public Health Interventions Advisory Committee (PHIAC) of NICE supported the use of GPPAQ as a validated tool developed to support brief interventions. 
- Moderately inactive people

- Moderately active people

- Active people

Each segment will be associated with a prototypical model of activity (see Table 1), defining:

a) One or two standards of weekly volume of activity (basic and/or gold), and

b) An appropriate progressive path of pursuing.

At the moment, as first stage of development of the model, we have planned to define 5 progressive paths, easily identifiable in their rationale and content, in order to make them both immediately understandable by users and available to be modeled at the computational level. Each progressive path will be marked by an image synthesizing its functional meaning and therefore facilitating the identification of the type of user fitting it (i.e. "Speedy Gonzales"; "Two Step"; "Diesel 
Table 1. Users segmentation and prototypical models of activity.

\begin{tabular}{cccc}
\hline Profiles of users & Basic standard & Gold standard & $\begin{array}{c}\text { Progressive paths of pursuing } \\
\text { (week 1, 2, 3, 4, 5-8; percentage of } \\
\text { coverage of the standard chosen) }\end{array}$ \\
\hline Inactive & $>450$ & - & (Try and check) $0,3 / 0,5 / 0,5 / 0,75 / 1$ \\
\hline Moderately inactive & $>450$ & 900 & $\begin{array}{c}\text { (Diesel engine) } \\
0,5 / 0,75 / 0,75 / 1 / 1\end{array}$ \\
\hline Moderately active & 900 & 1800 & $\begin{array}{c}\text { (Two step) } \\
0,75 / 0,75 / 1 / 1 / 1\end{array}$ \\
\hline Active & - & 1800 & $\begin{array}{c}\text { (Speedy Gonzalez) } 0,75 / 1 / 1 / 1 / 1 \\
(\text { All in one) } \\
1 / 1 / 1 / 1 / 1\end{array}$ \\
\hline
\end{tabular}

Procedure of goals and progressive program setting

Each user can be asked to fulfill the GPPAQ on a web-based platform. The platform will make it explicit the profile of current activity (among the possible 4) the user will be resulted classified. Basic pockets of evidence-based knowledge will be provided in order to highlight the risks/benefits associated with the profiles.

Then, the user is asked to confirm his/her intention to design a program of PA. If the user accepts, the procedure of goal and path starts. Figures $1 \mathrm{a}$ and $1 \mathrm{~b}$ detect the workflow of the procedure.

First, the user will be advised as to the standard(s) associated with the segment s/he has been classified. Advices, however, will not be normative, in the sense that they will be provided in terms of suggestions rather than imposed to users. Thus, the chance to choose a standard (and a progressive path) by one's own will be left to every user.

Once the client will have confirmed or changed the standard, this will be the Personal Goal (PG). Thus: $P G=S t$, where $P G$ stands for Personal Goal, St for the chosen Standard.

Second, the user will be provided with a default progressive path, the one associated with the segment (according to the scheme reported in Table 1). Yet, it will be highlighted that s/he has the chance to change it, if $\mathrm{s} /$ he should find it preferable a different progressive path (or the all-in-one path). A brief textual and graphical presentation of each path, with the associated rationale will be provided, in order to make it explicit which kind of need and attitude it fits with ${ }^{2}$.

Also, after having started the program, the user will have the possibility to change goal and path at any time. The new program will start always on the nearest Monday ${ }^{3}$.

\footnotetext{
2. Standard, goals and paths will be provided both in terms of METs and amount of time.

${ }^{3}$ Incidentally, as further development, it will be worth enabling the system to provide the suggested standard and progressive path as function of the user's socio-psychological profile as well as socio-ecological scenario she/he is part of.
} 


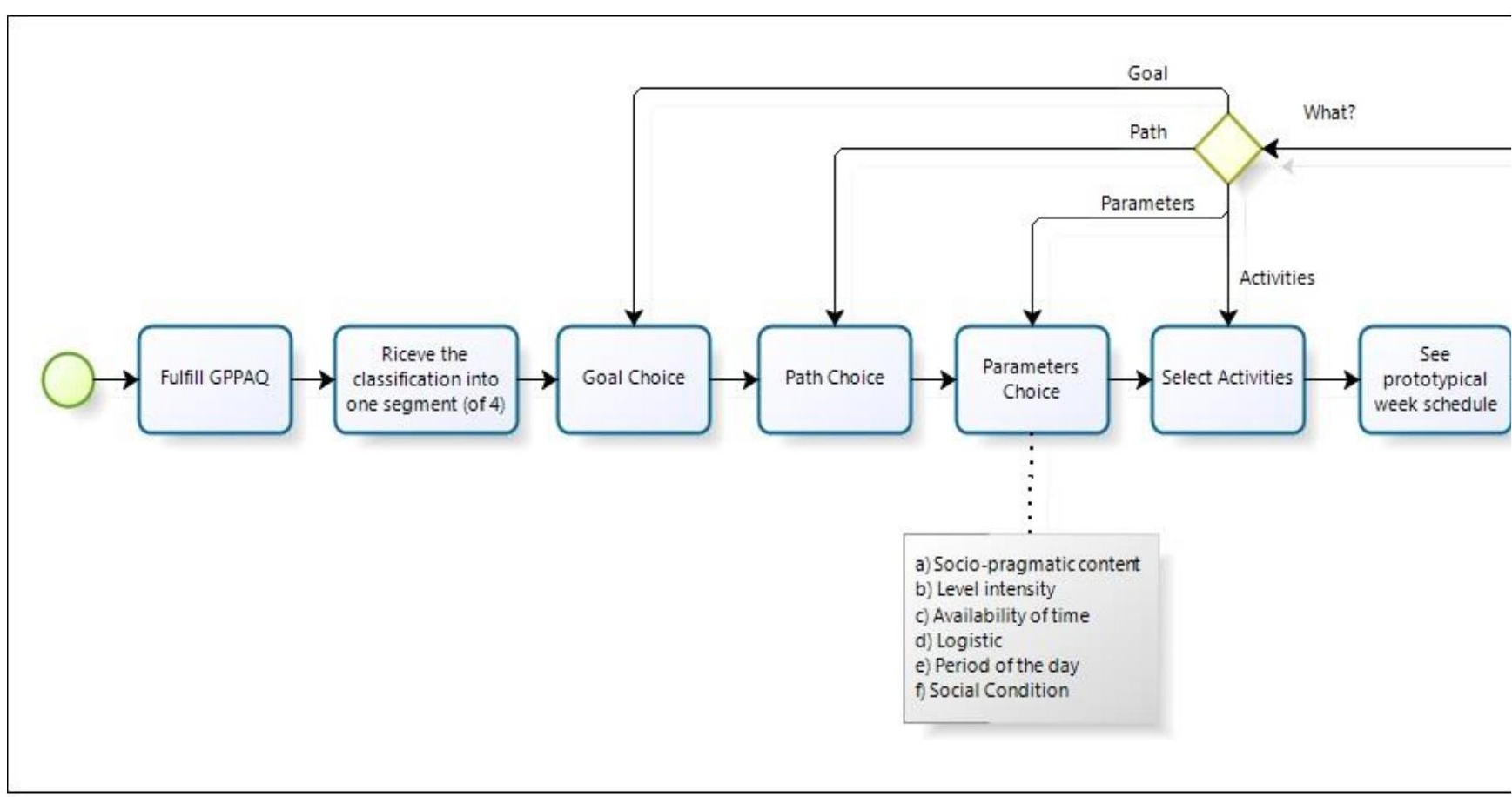

Figure 1. a. The procedure of the physical activity planning. A global look. 


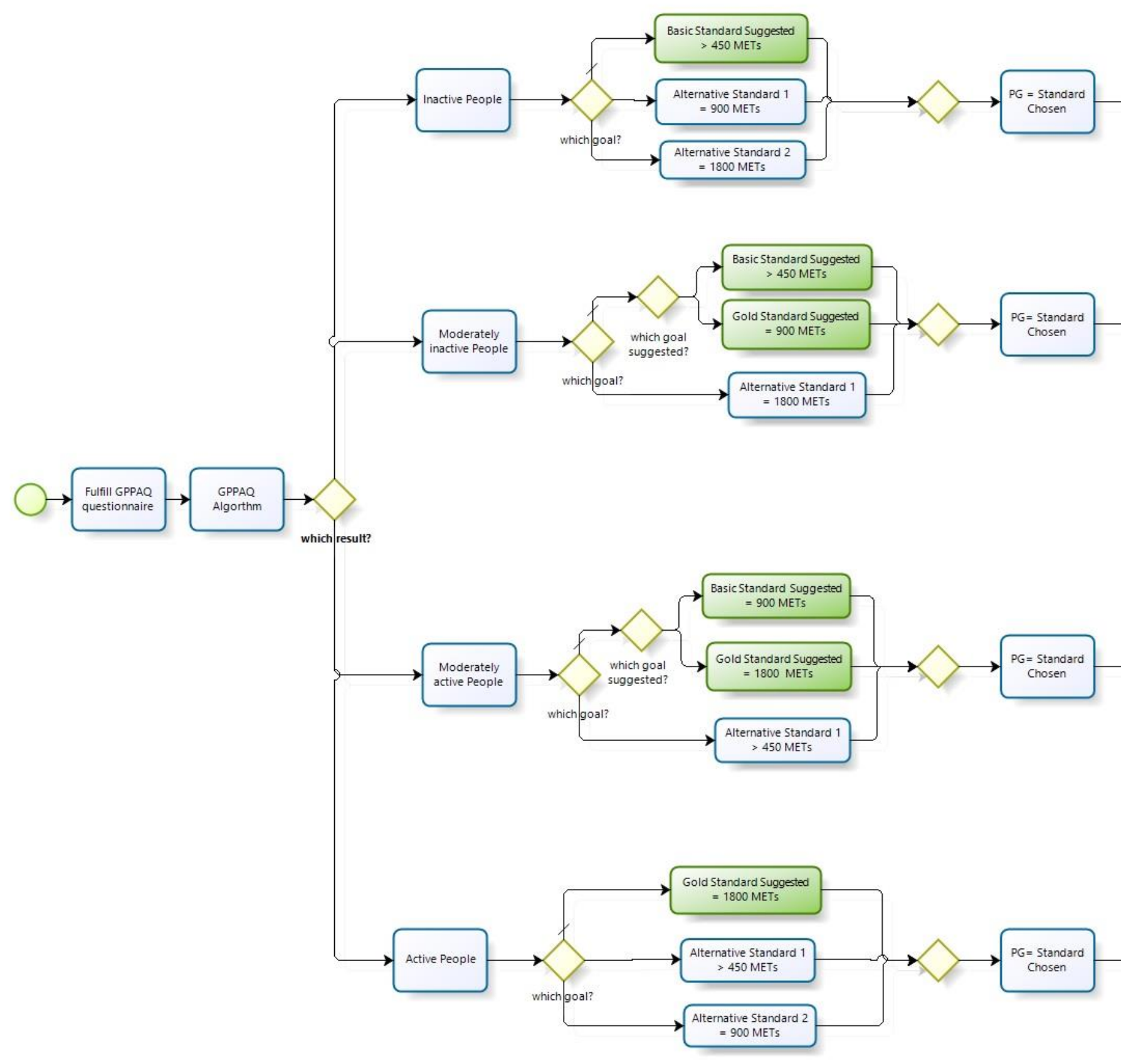

Figure 1. b. The procedure of goal and path setting (Prototypical paths and goals in green).

161 The selection of the content of physical activities

Once goal and progressive path are set, the user will be asked to choose the content of the physical activities, to build her/his program.

To this end, a dataset of blocks of activity has been defined. Each block is a 10-minute unit of PA (e.g. housing, washing glasses, walking) associated with the corresponding METs.

The user will be asked to choose the blocks of activity fitting with his/her constraints/preferences. The user will do so by selecting characteristics of activities as defined by a set of parameters. The 
selection of a certain characteristic will correspond to the deactivation of a filter operating upon the dataset of blocks. The parameters are the following:

a) the content of the activity (e.g. sport activity, leisure, gardening, housing, and so forth).

b) the level of intensity of the activity (low-moderate-high)

c) the user's availability of time (high - i.e. HIGH: more than 3 hours daily/MIDDLE: 1-3 hours/LIMITED: less than 1 hour)

d) the venue of the activity (indoor/outdoor/both)

e) the moment of the day related with the activity (morning/afternoon/evening/not depending on the moment of day)

f) the social condition of the activity (alone/requiring at least a couple/requiring a team)

User will be able to select all aspects s/he wants, in order to personalize own set of blocks of activity fitting with own project.

Blocks of activity will be classified in accordance with each parameter (Table 2 provides an exemplificative excerpt of the classification of activity used for this purpose). In this way, the user's activation of one parameter will correspond to the selection of only the blocks tagged by those modalities and the deselection of others.

Thus, eventually, the platform will provide the user of the fitting blocks of activity, namely the ones corresponding to her/him condition and preferences (i.e. her/his project).

It is worth adding that, for every expected combination, the dataset will hold blocks of activity which one can expect are able to meet the need of persons of different socio-economic level as well as gender. Moreover, blocks for people with special need will be provided. This will be so because these sources of variability in the users' preference are associated with sensible data. Therefore, not being possible to ask data about them directly to users, such sources will be considered downhill, by providing the user with a set of alternatives encompassing them. 
Table 2. Excerpt of the classification of activity.

\begin{tabular}{|c|c|c|c|c|c|c|c|c|c|c|c|c|c|c|c|c|c|c|}
\hline \multirow[b]{3}{*}{ Content } & \multirow{3}{*}{$\begin{array}{r}\text { Block Activity } \\
\text { Name }\end{array}$} & \multirow[b]{3}{*}{$\begin{array}{l}\text { MET value } \\
\text { (for } 1 \\
\text { minute) }\end{array}$} & \multicolumn{16}{|c|}{ Parameters } \\
\hline & & & \multicolumn{3}{|c|}{ Level } & \multicolumn{3}{|c|}{ Time } & \multicolumn{3}{|c|}{ Venue } & \multicolumn{4}{|c|}{ Moment of day } & \multicolumn{3}{|c|}{ Social Condition } \\
\hline & & & Low & $\begin{array}{l}\text { Mode } \\
\text { rate }\end{array}$ & High & $\begin{array}{c}\text { High } \\
(>3 \\
h / d) \\
\end{array}$ & $\begin{array}{l}\text { Middl } \\
e \quad(1- \\
3 h / d)\end{array}$ & $\begin{array}{c}\text { Limit } \\
\text { ed }(<1 \\
h / d)\end{array}$ & $\begin{array}{c}\text { Indoo } \\
r\end{array}$ & $\begin{array}{c}\text { Outd } \\
\text { oor }\end{array}$ & Both & $\begin{array}{l}\text { Morn } \\
\text { ing }\end{array}$ & $\begin{array}{l}\text { After } \\
\text { noon }\end{array}$ & $\begin{array}{c}\text { Eveni } \\
n g\end{array}$ & $\begin{array}{c}\text { Not } \\
\text { depen } \\
\text { ding }\end{array}$ & Alone & $\begin{array}{c}\text { Coupl } \\
e\end{array}$ & Team \\
\hline $\begin{array}{c}\text { Household } \\
\text { Activities }\end{array}$ & $\begin{array}{l}\text { Interior } \\
\text { Cleaning }\end{array}$ & 3.01 & No & Yes & No & No & No & Yes & Yes & No & No & No & No & No & Yes & Yes & No & No \\
\hline $\begin{array}{c}\text { Household } \\
\text { Activities }\end{array}$ & Laundry & 2.07 & Yes & No & No & No & No & Yes & Yes & No & No & No & No & No & Yes & Yes & No & No \\
\hline $\begin{array}{c}\text { Household } \\
\text { Activities }\end{array}$ & $\begin{array}{c}\text { Sewing, } \\
\text { repairing, and } \\
\text { maintaining } \\
\text { textiles }\end{array}$ & 1.5 & Yes & No & No & No & Yes & No & Yes & No & No & No & No & No & Yes & Yes & No & No \\
\hline $\begin{array}{c}\text { Household } \\
\text { Activities }\end{array}$ & $\begin{array}{c}\text { Storing interior } \\
\mathrm{HH} \text { items, } \\
\text { including food }\end{array}$ & 3.39 & No & Yes & No & No & No & Yes & Yes & No & No & No & No & No & Yes & Yes & No & No \\
\hline $\begin{array}{c}\text { Household } \\
\text { Activities }\end{array}$ & $\begin{array}{c}\text { Housework, } \\
\text { n.e.c. }\end{array}$ & 2.51 & Yes & No & No & No & No & Yes & No & No & Yes & No & No & No & Yes & Yes & No & No \\
\hline $\begin{array}{c}\text { Household } \\
\text { Activities }\end{array}$ & $\begin{array}{c}\text { Food and drink } \\
\text { preparation }\end{array}$ & 2.16 & Yes & No & No & No & No & Yes & No & No & Yes & No & No & No & Yes & Yes & No & No \\
\hline $\begin{array}{c}\text { Household } \\
\text { Activities }\end{array}$ & $\begin{array}{c}\text { Food } \\
\text { presentation }\end{array}$ & 2.38 & Yes & No & No & No & No & Yes & Yes & No & No & No & No & No & Yes & Yes & No & No \\
\hline $\begin{array}{c}\text { Household } \\
\text { Activities }\end{array}$ & $\begin{array}{c}\text { Kitchen and } \\
\text { Food Clean-Up }\end{array}$ & 2.54 & Yes & No & No & No & No & Yes & Yes & No & No & No & No & No & Yes & Yes & No & No \\
\hline
\end{tabular}




\section{The week planning of the activity}

The blocks of activity selected in the previous step will work as the "lego" units in the following step, devoted to the building of the weekly schedule of the personalized program of PA.

On one side of the screen the user will find the blocks of activity s/he has selected (fitting blocks). Form and color of blocks will indicate their main characteristics (e.g. form for the type of activity and color for the level of intensity). Information concerning other parameters will be provided by means of the block position on the screen. Moreover, each block will report the corresponding METs inside.

On the other side of the screen, the user will find an empty week agenda plan (segmented in units of 10 minutes) to be used for distributing the fitting blocks over the week.

User will be invited to plan her/his own schedule, placing the blocks within the week agenda plan, taking the block from the set of fitting blocks exposed on the other side of the screen.

Figure 2 provides an example of week plan of the PA.

In parallel with the planning, the platform will provide indicators of the level of consistency of the schedule with the Personalized Goal. More in particular, the following indexes will be provided:

A) The global amount of MET set over the week $(G A w)$. Thus, GAw represents the total amount of METs corresponding to the blocks scheduled.

$G A_{w}$ is calculated in the following way:

$\mathrm{GA}_{\mathrm{w}}=\sum_{i=1}^{7} \sum_{k=1}^{n} B_{i k}$

Where $B$ is the METs distributed over the week, i represent the generic day in a week, $\mathrm{n}$ is the number of activity. B) The level of coverage for the week $\left(C V_{w}\right)$, namely the ratio in percentage of GAwout the Personal Goal for that week (as defined by the path chosen). $C V_{w}$ can vary from 0 to $100 \%$. The maximum $C V_{w}$ is given when the MET scheduled in the week $\left(G A_{w}\right)$ are the ones foreseen by the path chosen. If $G A_{w}$ corresponds to the Personal Goal, $C V_{w}$ will be $100 \%$.

$C V_{w}$ is calculated in the following way:

$\mathrm{CV}_{\mathrm{w}}=100^{*} \mathrm{GA}_{\mathrm{w}} / \mathrm{PG}_{\mathrm{w}}$

Where PGw is the Personal Goal of the week, as defined by the path chosen

C) The global distribution of the MET over the week $\left(D_{w}\right)$. This index esteems the homogeneity/concentration of the activity across the days of the week.

$D_{w}$ is calculated in the following way: $D=\frac{M A X}{M I N}$

where MAX is the amount of METs planned in the day of the week with the maximum amount of daily METs; MIN is the amount of METs planned in the day in the week with minimum amount of daily METs.

$D_{w}$ will be expected not to be higher than 1,75 . In formulas:

$$
D \leq 1,75
$$

This means the MAX value should not be higher than the double of MIN. This is so for the sake of defining a criterion guiding the user to schedule the activities (and relative METs) homogeneously over the week.

D) The fitness of the distribution $\left(F_{w}\right)$ respect on the basic distribution suggested by literature (i.e. METs distributed over 3 days). This index esteems the homogeneity of the distribution of METs over the week. This will be done in terms of the computation of how many days of the week present an amount of METs scheduled that is over the level of the standard concentration.

$F_{w}$ is calculated in the following way.

First, the level of standard concentration is defined, in the following way.

$\mathrm{CON}_{w}=\left(G A_{w} / 3\right)+0,2\left(G A_{w} / 3\right)$

Thus, the level of concentration is given by one third of the amount of MET scheduled for the week $(G A w)$, increased of $20 \%$ of it.

Then, $F_{w}$ is given by the number of days having METs higher than $C O N_{w}$. 


\begin{tabular}{|c|c|c|c|c|c|c|c|c|c|}
\hline & MON & TUE & WED & THU & FRI & SAT & SUN & \multicolumn{2}{|c|}{$\begin{array}{c}\text { Personal blocks of } \\
\text { activity }\end{array}$} \\
\hline $8^{.00}$ & $\begin{array}{l}\text { walking } \\
38 \\
\text { METs }\end{array}$ & & $\begin{array}{l}\text { housework } \\
25.1 \\
\text { METs }\end{array}$ & & & & & swimming & \\
\hline $8^{.10}$ & $\begin{array}{l}\text { running } \\
75 \\
\text { METs }\end{array}$ & & $\begin{array}{l}\text { housework } \\
25.1 \\
\text { METs }\end{array}$ & & & & & cycling & \\
\hline $8^{.20}$ & $\begin{array}{l}\text { walking } \\
38 \\
\text { METs }\end{array}$ & & & & & & & $\begin{array}{l}\text { running } \\
\text { 75METs }\end{array}$ & \\
\hline $8^{30}$ & & & & & $\begin{array}{l}\text { running } \\
75 \\
\text { METs }\end{array}$ & & & aerobics & \\
\hline $8^{.40}$ & & & & & $\begin{array}{l}\text { running } \\
75 \\
\text { METs }\end{array}$ & & & dancing & \\
\hline $8^{.50}$ & & & & & & & & walking & \\
\hline $9^{.00}$ & & & $\begin{array}{l}\text { dancing } \\
45 \text { METs }\end{array}$ & & & & & housework & \\
\hline $9^{.10}$ & & & $\begin{array}{l}\text { dancing } \\
45 \text { METs }\end{array}$ & & & & & & \\
\hline $9^{.20}$ & & & $\begin{array}{l}\text { dancing } \\
45 \text { METs }\end{array}$ & & & & & & \\
\hline $9^{.30}$ & & & & & & & & & \\
\hline $9^{.40}$ & & & & & & & & & \\
\hline $9^{.50}$ & & & & & & & & & \\
\hline METs/die & 151 & & 185 & & 150 & & & Tot METs & $\begin{array}{l}\text { Tot } \\
\text { Min }\end{array}$ \\
\hline Min/Die & $30^{\prime}$ & & $50^{\prime}$ & & $20^{\prime}$ & & & 486 & $100^{\prime}$ \\
\hline
\end{tabular}

Figure 2. An example of week schedule of physical activity.

57 Self-Monitoring 
The user will be asked to check the scheduled activities daily, accordingly to a 4 point scale ("I did more!"; "I did them!"; "I did them partially"; "I did not them") associated with a corresponding icon (e.g. a smile, a sorrow face). Each day will be classified accordingly (namely, as a "I did more!" day, a "I did them" day and so forth)

In order to calculate the indexes indicated below (§ 8.2), the modality "I did more!" is considered conventionally being equivalent to 1.25 times the scheduled METs of the day. The modality "I did them partially" is considered conventionally being equivalent to 0.5 time the scheduled METs of the day.

In the event the user skips the daily monitoring, the first time s/he accesses newly to the platform, $\mathrm{s} /$ he will be asked to check the activity not monitored before going on. More in particular, the user will be asked if the not monitored activities have to be considered not accomplished. If the user will answer "Yes", all not monitored activities will be classified accordingly, as "I did not". If the user will answer "No", s/he will be asked to check them day-by-day.

\section{Day and Week Feedback}

The system will provide a daily and a weekly feedback, respectively at the end of the day and of the week.

\section{Daily feedback}

The daily feedback will be aimed at reinforcing the user in the case s/he has accomplished the daily task or to motivate/support her/him in completing it in the following day(s).

To this aim, a synthetic feedback will be provided, according to the following decisional tree (see Figure 3).

A) if the daily amount of METs, or more, has been performed, the system will provide a positive feedback (e.g. "Very good- you worked for your health today! Take you ready for tomorrow") to the user.

B) if the daily amount of METs has not been reached, the user will be asked if s/he intends/is able to reschedule the following day(s) so as to recuperate the unaccomplished amount of METs.

B1) if the user answers "Yes", the system will provide a reinforce message (e.g. "nice choice; I see you are taking very seriously your health!") and the week schedule will appear on the screen, together with a multiple-choice questionnaire on the motives of the inability to accomplish the daily activities. Moreover, a tutorial will support the rescheduling of the week plan, providing one or more appropriate simple strategies for recuperation (e.g. to change duration and/or intensity of activity; to add new activity; to displace the task in another moment of the day); finally, the tutorial will warn as to the constraints concerning the distribution of the activities over the week - this in order to avoid that the rescheduling could produce an unhealthy distribution of METs on the week ${ }^{4}$.

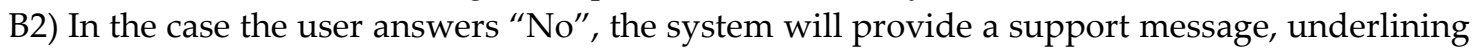
that what is important is to understand the reasons of the missed accomplishment, in order to find the fittest week schedule. Also in this case, the user will be asked to fulfill the questionnaire on the motives of failure (the same of B1). Moreover, s/he will be advised to check if the failure has to be interpreted as contingent or systematic (i.e. if contingent, then no mind; if it is the effect of a systematic motive, then the user will be invited to revise the following part of the week plan).

Weekly feedback

\footnotetext{
${ }^{4}$. Incidentally, it is worth noting a line of development of the system entailed in the architecture outlined above - joining information obtained by the questionnaire and by the rescheduling (the former provided by the user, the latter extracted by the system by means of the computation of the difference between schedule and reschedule) will be possible to identifying profiles of user characterized by specific matching between motives of failure and strategies of facing them.
} 
The weekly feedback concerns the appropriateness of the schedule for the user. It is provided at the end of the week and it is aimed at checking the validity of the schedule (i.e. its appropriateness for the user) and/or to modify-modulate it in order to increase its validity for the user.

\section{Weekly report}

A week report of the activity will be produced. This report will be based on the daily selfmonitoring (see § 7) and will provide the following summary statistics:

1. the amount of METs performed in the week $\left(P E R F_{w}\right)$;

2. the distribution of METs over the week (Monday, Tuesday...) and previous weeks (i.e. week $1,2)$;

3. the distribution of METs over the fitting blocks of activity;

4. the distribution of METs over categories of activity (the ones identified by parameters: e.g. content, venue and so forth);

5. the distribution of the 4 type of days ("I did more!", "I did them") over the last 4 weeks;

6. the distribution of the type of days ("I did more!", "I did them") over the last 4 weeks differentiated for categories of activity (the ones identified by parameters).

Weekly feedback.

A synthetic feedback will be provided, according to the following decisional tree (see Figure 4).

\section{Condition 1. Week success}

If the user has accomplished the personalized goal of the week, then s/he will receive a reinforcing message and the invitation to deal with the new week plan.

The user will be provided with the indication of the amount of METs defined by her/his progressive path for the incoming week. S/he will be asked to confirm the chosen Personalized Goal for the incoming week and to schedule the activities over the week accordingly.

In the case of users classified as "moderately inactive" and "moderately active", who had chosen the basic standard, if their personalized goal corresponds to the $100 \%$ of the basic standard and if their personalized goal has been accomplishing systematically for the last - respectively - 6 and 3 weeks, then they are proposed to move to the gold standard (1800 METs). To this end, a message of compliments will be appear on the screen, underlining the value of the performance and the chance to get a more ambitious, healthy purpose.

In order to support the user's rescheduling, the previous week plan will appear on the screen, in the case with the indication of the amount of additional METs required as well as the possibility of revising the types of blocks of activity selected the week before. Indicators described in paragraph 6 (e.g. GAw, the global amount of METs scheduled for the week) will be provided as well.

\section{Condition 2. Week failure}

If the week goal has not been accomplished, the system will calculate a set of statistics in order to provide a framework supporting the user's decision making.

In particular, statistics will concern:

a) the relative amount of METs not accomplished in the current week respect on the scheduled METs $\left(U N C_{w}\right) . U N C_{w}$ is computed as the difference between the scheduled METs for the week and the METs accomplished divided the scheduled METs. In formulas:

$\mathrm{UNC}_{\mathrm{w}}=100^{*}\left(\mathrm{GA}_{\mathrm{w}}-\mathrm{PERF}_{\mathrm{w})}\right) / \mathrm{GA}_{\mathrm{w}}$;

b) the $U N C_{w}$ concerning the previous weeks of the program;

c) the good ("I did more" and "I did them") and the bad ("I did them only partially" and I did not them") days of the week;

d) the distribution of the $U N C_{w}$ over the types of activity (e.g. between content; between moment of daytime, venue and so forth); 
e) the frequency motives of the failures identified by the questionnaire (both global statistics and disaggregated for days and types of activity)

A tutorial will be proposed to the users, with advices concerning the ways of facing the critical issues highlighted by statistics a-e. To this end, the numeric values will be presented in ordinal scale too. More specifically,

$U N C_{w}<20$ "this aspect is not problematic";

$21<U N C_{w}<39$; "this aspect is moderately problematic";

$U N C_{w}>40^{\prime \prime}$ this aspect is highly problematic".

The advices will be organized in hierarchical way, moving from the proposal of strategies (among the ones functional to the critical issues associated with the user) having the lowest impact on the plan to the one having the highest.

The personalized combination of advices will be calculated by means of the matrix critical issuesstrategies for facing them. For each critical issue (encompassing both the detection of failures and the motives identified by the user) a pertinent set of strategies will be proposed. 


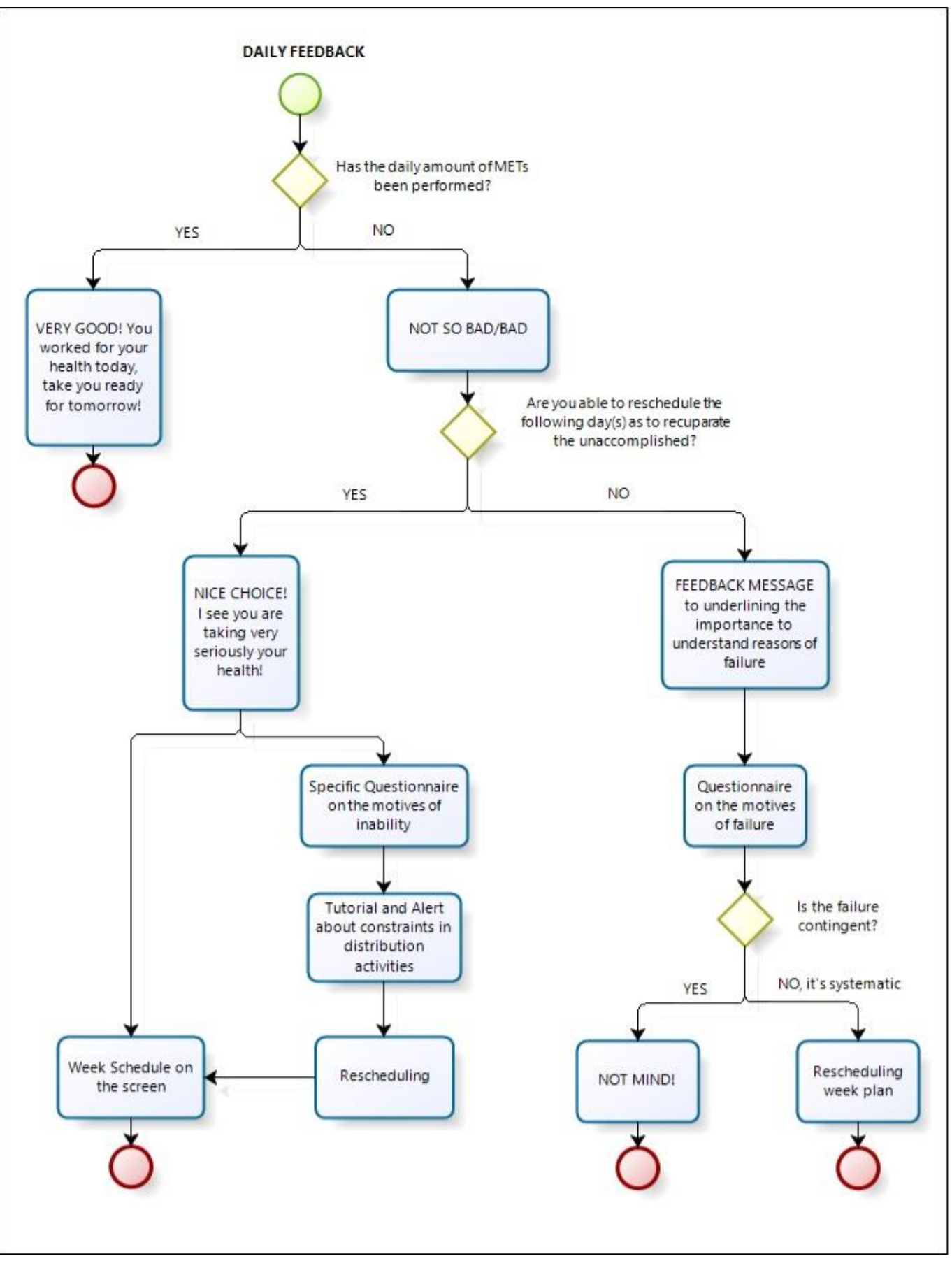

Figure 3. Decisional tree of the daily feedback. 


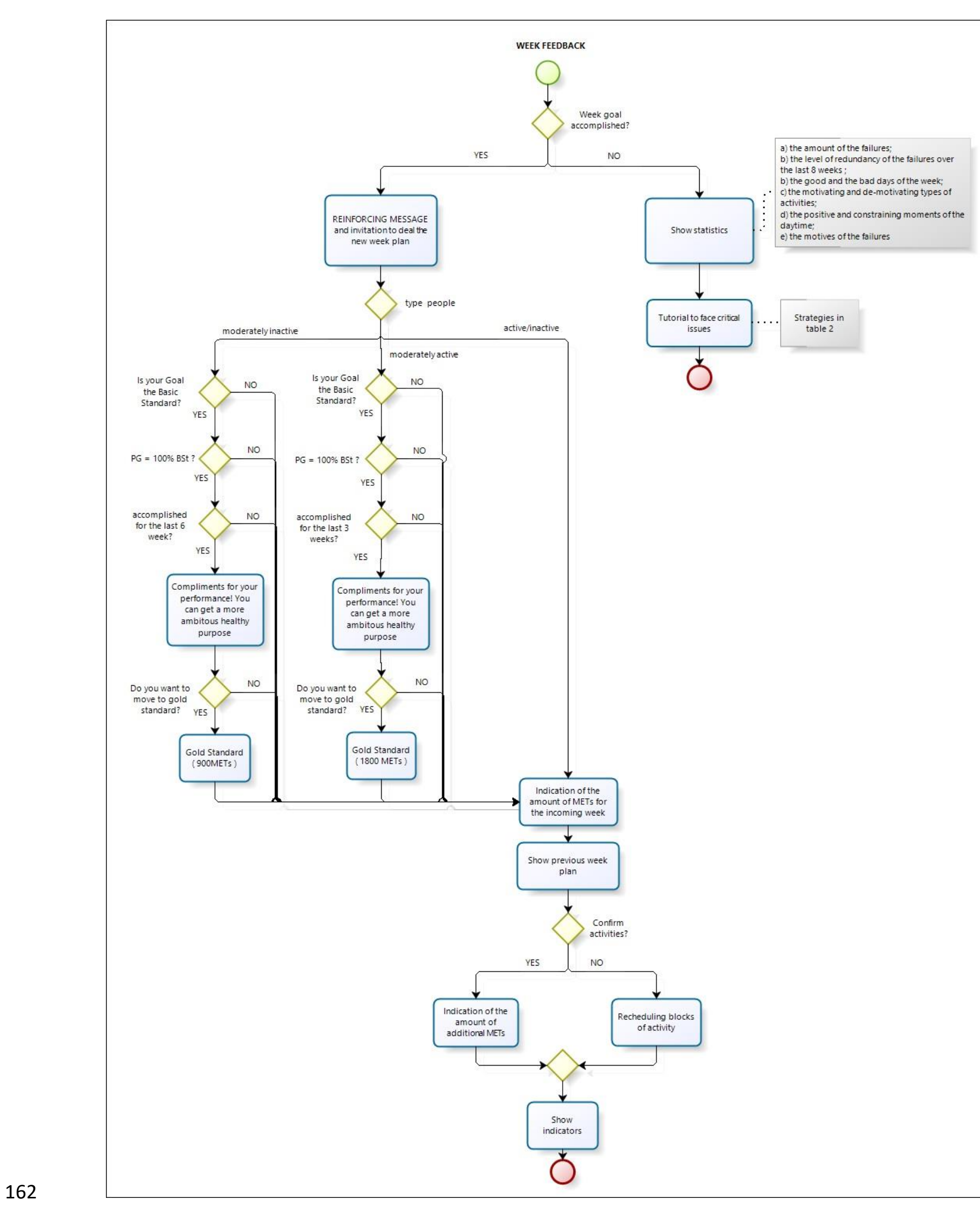

Figure 4. Decisional tree of the week feedback. 
To take advantage of using this innovative web-based application, a basic computer literacy is required, because the algorithm is designed to work in Windows and developed to work in a very intuitive environment, including visual selections. To further improve the compliance to the use of this tool, initial instructing for the users will be provided. Therefore, advanced IT skills are not required.

\section{Discussion}

In the perspective of reducing the impact of NCDs, we have developed an innovative webbased person-centred quantitative function to foster individual motivation towards physical exercise. Based on the GPPAQ and by computing the METs corresponding to each profile of exercise levels, we have set a quantitative function able to set individual goals and paths. This approach allows to define evidence-based standardised profiles, personalized goals of physical activity being functional to the purpose of maintaining or gaining health benefits, as well as the algorithms (type and duration of physical activity) needed to reach these goals.

Available evidence about the effectiveness of lifestyle intervention, including regular PA, for the prevention and management of several NCDs [3], does not correspond to an adequate effort in terms of management strategies for chronic diseases by National Health Systems (NHS), particularly in terms of preventive care, with the result of underdiagnosis and undertreatment of these conditions and a consequent detrimental impact on public health and socio-economic burden, as underlined by the World Health Organisation (WHO) [3]. To better understand how the choice of behaviours associated with a negative lifestyle is crucial in the relationship with chronic diseases responsible for the greatest number of deaths, it is useful to refer to the 3-four-50 model [11]. This model emphasizes that the 3 main components of the modern lifestyle, such as smoking, poor diet, and low levels of PA, contribute to the incidence, severity, and economic burden, of the four most relevant diseases for the current generation, such as cancer, cardiovascular and cerebrovascular diseases, type 2 diabetes, and pulmonary diseases, responsible for over $50 \%$ of deaths all around the world. This alarming scenario clearly requires promoting successful strategies to hinder the growing prevalence of negative lifestyle-related diseases. If we go beyond this obvious observation, considering that everyone knows that smoking habits, alcoholism, unhealthy diet, and a sedentary lifestyle are dangerous for personal wellbeing, it is necessary to look for the behavioural aspects that lead people to adopt lifestyles that threaten their lives. People usually think of the price to pay for wellbeing (increased PA, radical change in eating habits) as immediate, while the short-term benefit of this approach usually goes unnoticed [12]. Moreover, people are overly optimistic about their ability to take corrective action [13].In this study we provided evidence-based standardised profiles and personalized goals of PA to be used through a dedicated platform that take into account people needs according to basal levels of PA thus increasing self-efficacy. We defined personalized path of PA by classifying different activities by their intensity, using the MET as a reference. MET is a largely adopted unit of measure of the PA. One MET is the rate of energy expenditure while sitting at rest. It is taken by convention to be an oxygen uptake of 3.5 milliliters per kilogram of body weight per minute or $1 \mathrm{kcal} / \mathrm{kg} / \mathrm{h}$. Moderate-intensity PA refers to the PA that is performed at 3.0-5.9 times the intensity of rest (3.0-5.9 METs). Vigorous-intensity PA refers to PA that is performed at 6.0 or more times the intensity of rest (>6 METs) [14].

According to WHO guidelines adults should do at least 150 minutes of moderate-intensity aerobic PA or at least 75 minutes of vigorous-intensity aerobic PA throughout the week or an equivalent combination of moderate- and vigorous-intensity activity. For additional health benefits, adults should increase their moderate-intensity aerobic PA to 300 minutes per week or engage in 150 minutes of vigorous-intensity aerobic PA per week [15].

These statements are consistent with the guidelines proposed by the U.S. Department of Health and Human Services that say that:" When adults do the equivalent of 150 minutes of moderateintensity aerobic activity each week, the benefits are substantial. These benefits include lower risk of 
premature death, coronary heart disease, stroke, hypertension, type 2 diabetes, and depression. Not all health benefits of PA occur at 150 minutes a week. As a person moves from 150 minutes a week toward 300 minutes (5 hours) a week, he or she gains additional health benefits. Additional benefits include lower risk of colon and breast cancer and prevention of unhealthy weight gain." [16]. Moreover, they say that: "Aerobic PA should preferably be spread throughout the week. Research studies consistently show that activity performed on at least 3 days a week produces health benefits. Spreading PA across at least 3 days a week may help to reduce the risk of injury and avoid excessive fatigue."

However, our proposal lacks assessment about participants' motivation and cultural/psychological determinants of being engaged in physical activity. This issue could limit the compliance to the use of the application by consumers.

Considering that NHS must deal with the progressive reduction of available resources, the realization of evidence-based public health programs aimed at promoting lifestyle interventions that are cost-effective and feasible in community settings is a crucial issue for researcher, health managers, and policymakers. Behaviorally based strategy addressing participation to PA programs have been demonstrated to be cost-effective compared to center-based exercise programs [17]. In this context, our proposal might be easily accessible, cost-effective, and reliable to allow both measuring and enhancing participation of large population to PA programs in community settings. This paper might be used also as a framework for implementing the development of other community-based lifestyle interventions. However, we provided only a theoretical model that requires to be implemented in further research.

Ethics approval and consent to participate. N/A

\section{Consent for publication. N/A}

\section{Competing interests. None}

238 Funding. No external funding for this paper

Acknowledgments. Authors are grateful to the Euro Mediterranean Scientific Biomedical Institute (ISBEM) of 240 Mesagne (Brindisi, Italy).

241 Authors' Contribution: GI, PP, and AM designed the study; GI, FG, AM, and GDP defined the standardised profiles of recommended PA and developed personalized goals of PA; GC, AD, and PP produced algorithms to reach personalized goals of PA; GI, GC, MR, MP and AM drafted the paper. All authors read and approved the final manuscript.

Availability of data and materials. statistical code and dataset freely available upon reasonable request to Prof.

246 Giovanni Iolascon, Head of Department at University of Campania (Naples, Italy), by using the following email address: giovanni.iolascon@unicampania.it

\section{References}

1. World Health Organization. (2012). Action plan for implementation of the European strategy for the prevention and control of noncommunicable diseases 2012-2016. Copenhagen, Denmark: World Health Organization, Regional Office for Europe.http://www.euro.who.int/en/healthtopics/noncommunicable-diseases/cancer/publications/2012/action-plan-for-implementation-of-theeuropean-strategy-for-the-prevention-and-control-of-noncommunicable-diseases-20122016.Accessed on 28th September 2019

2. World Health Organization (WHO). Non communicable disease: Country Profiles 2011. https://www.who.int/nmh/publications/ncd_profiles2011/en/. Accessed on 28th September 2019

3. Alwan, A. (2011). Global status report on noncommunicable diseases 2010. World Health Organization. https://www.who.int/nmh/publications/ncd_report2010/en/. Accessed on 28th September 2019 
4. NHS Health Development Agency (2004, June). Consumers and markets: The effectiveness of public health campaigns. HDA Briefing, 7, 1-4.

5. Landes, Xavier (2009), The Use of Incentives and the Promotion of Healthy Behaviours: TheCase of Unhealthy Food, National Collaborating Centre for Healthy Public Policy,ESSAY I MAY 2009

6. Jakab, Z. (2012, April). Patient Empowerment in the European Region-A Call for Joint Action. In Presentation at the First European Conference on Patient Empowerment, Copenhagen, 11th-12th April (p. 2).

7. EC. "Special Eurobarometer 472-Sport and Physical Activity." (2018): 1-133. https://data.europa.eu/euodp/data/dataset/S2164_88_4_472_ENG

8. Koeneman, M. A., Verheijden, M. W., Chinapaw, M. J., \&Hopman-Rock, M. (2011). Determinants of physical activity and exercise in healthy older adults: a systematic review. International Journal of Behavioral Nutrition and Physical Activity, 8(1), 142.

9. United States. Public Health Service. Office of the Surgeon General, National Center for Chronic Disease Prevention, Health Promotion (US), President's Council on Physical Fitness, \& Sports (US). (1996). Physical activity and health: a report of the Surgeon General. US Department of Health and Human Services, Centers for Disease Control and Prevention, National Center for Chronic Disease Prevention and Health Promotion.

10. Department of Health. The General Practice Physical Activity Questionnaire: AScreening tool to assess adult physical activity levels, within primary care. 2009[https://www.gov.uk/government/uploads/system/uploads/attachment_data/file/192453/GPPAQ _-_guidance.pdf]

11. 3Four50, www.3four50.com. Accessed on 28th September 2019

12. Mulgan, G. (2010). Influencing public behaviour to improve health and wellbeing. An independent report. London: United Kingdom Department of Health.

13. Chapin, J., \& Coleman, G. (2009). Optimistic bias: What you think, what you know, or whom you know?. North American Journal of Psychology, 11(1).

14. Piercy, KL, Troiano RP, Ballard RM, Carlson SA, Fulton JE, Galuska DA, George SM, Olson RD (2018). The physical activity guidelines for Americans. JAMA. 2018 Nov 20;320(19):2020-2028. doi:10.1001/jama.2018.14854.

15. World Health Organization. (2010). Global recommendations on physical activity for health. World Health

Organization.https://www.ncbi.nlm.nih.gov/books/NBK305057/pdf/Bookshelf_NBK305057.pdf.

Accessed on 20th March 2019

16. US Department of Health and Human Services. (2008). US Department of Health and Human Services 2008 physical activity guidelines for Americans. Hyattsville, MD: Author.http://www. health. gov/paguidelines/guidelines/default.aspx. Accessed on 20th March 2019

17. Sevick MA, Dunn AL, Morrow MS, Marcus BH, Chen GJ, Blair SN. Cost-effectiveness of lifestyle and structured exercise interventions in sedentary adults: results of project ACTIVE. Am J Prev Med. 2000 Jul;19(1):1-8. 
Figures
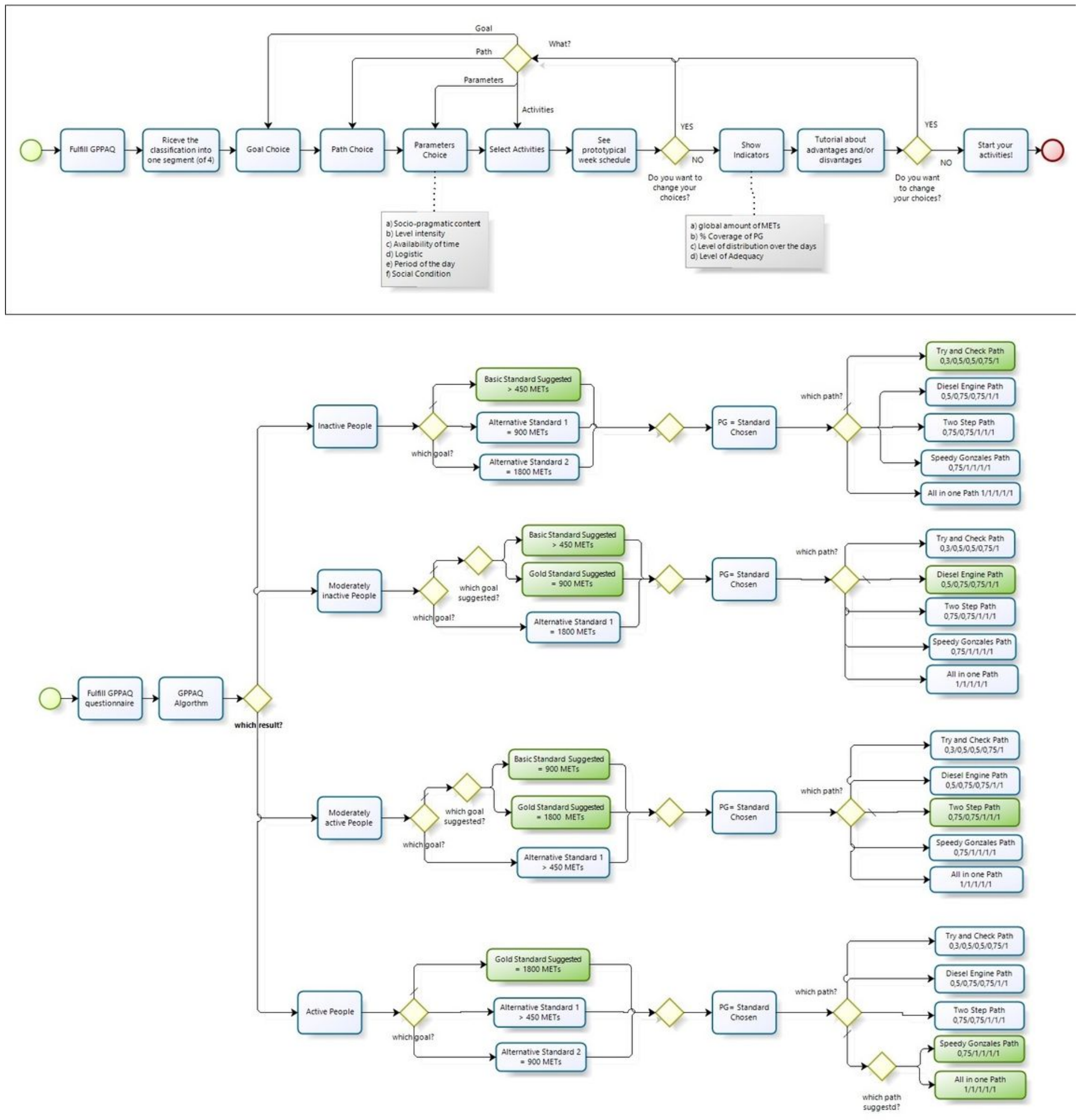

Figure 1

a. The procedure of the physical activity planning. A global look. b. The procedure of goal and path setting (Prototypical paths and goals in green). 


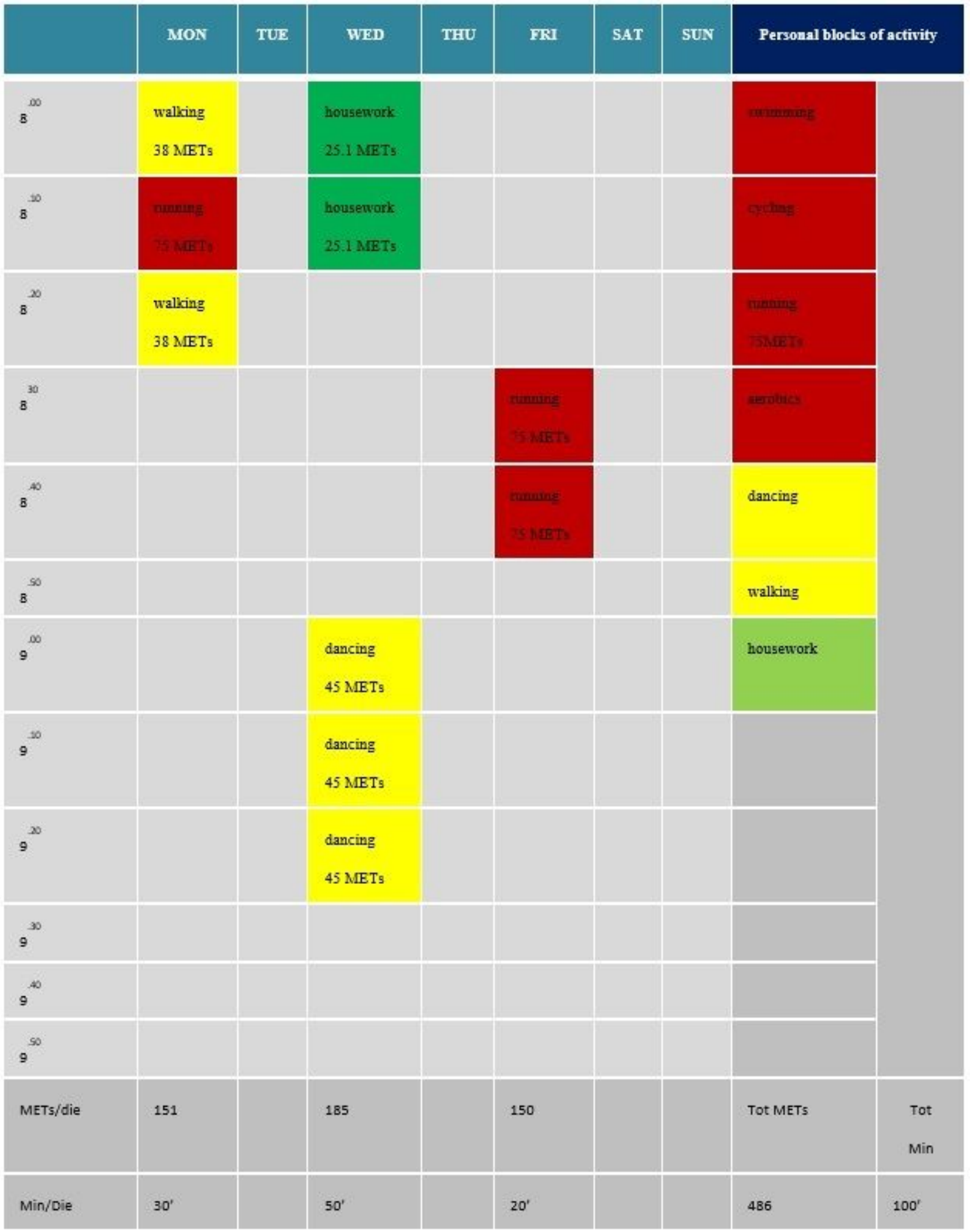

\section{Figure 2}

An example of week schedule of physical activity. 


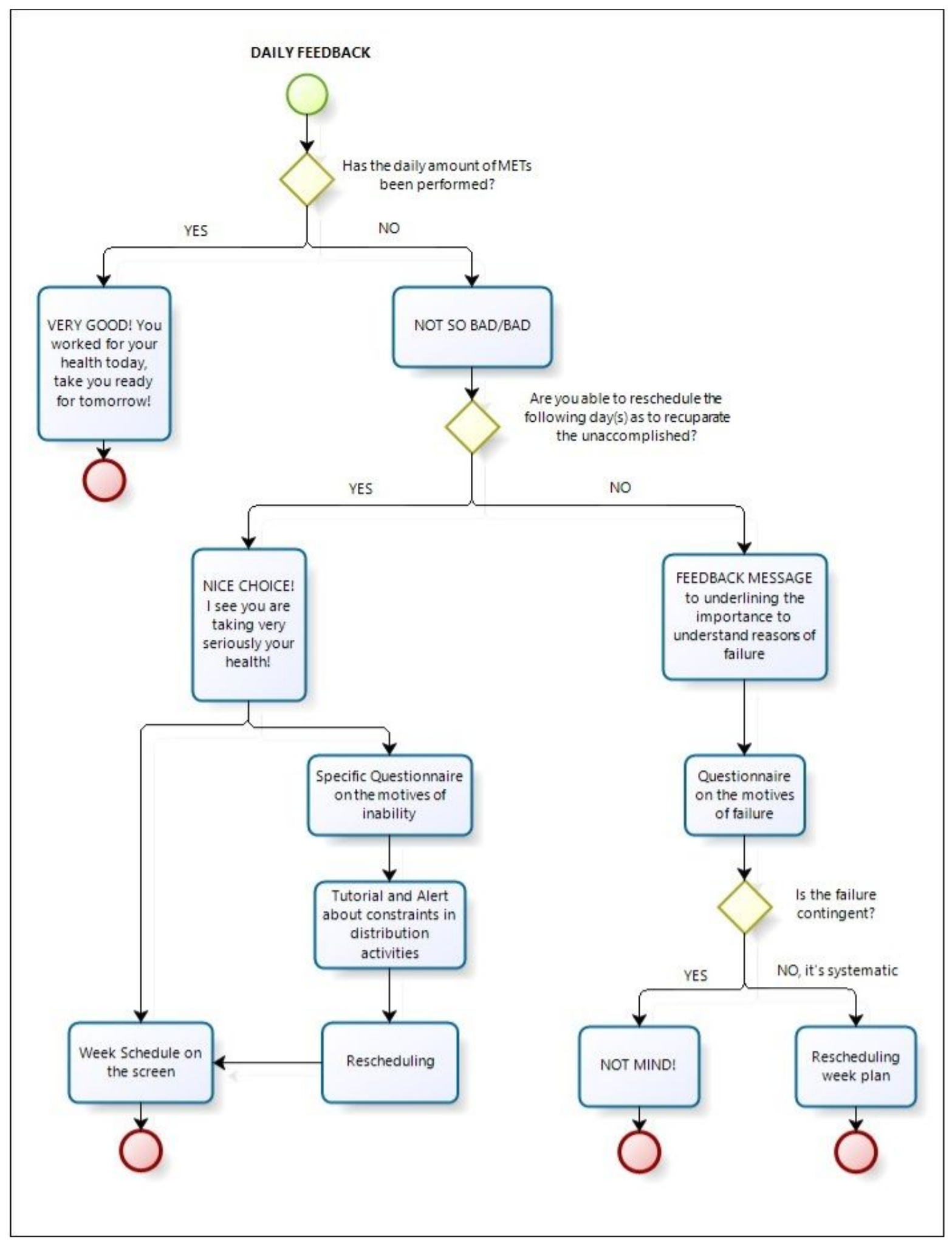

Figure 3

Decisional tree of the daily feedback. 


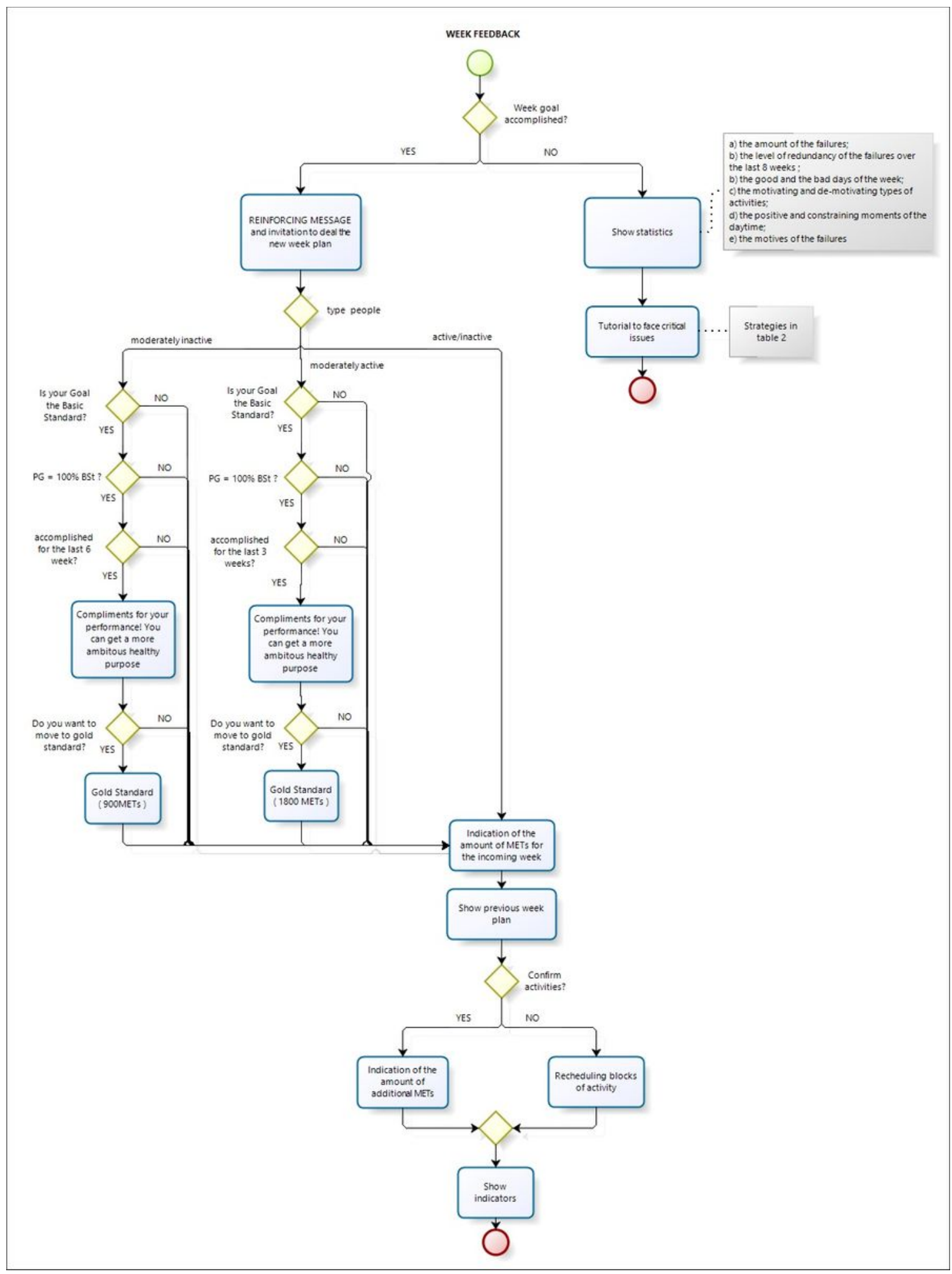

Figure 4

Decisional tree of the week feedback. 